Original Research Paper

\title{
Contextual Analyses of Attitudes toward Persons with Physical Disabilities
}

\author{
Christopher M. Amissah, Christopher K. Gadosey, Kingsley Nyarko and Collins B. Agyemang \\ Department of Psychology, University of Ghana, Legon, Accra, Ghana
}

Corresponding Author: Christopher M. Amissah Department of Psychology, University of Ghana, Legon, Accra, Ghana Email: chrismartinamissah@gmail.com

\begin{abstract}
Social desirability bias associated with attitudinal research can be minimized through contextual analyses. This study assessed attitudes toward persons with physical disabilities in three social contexts: Dating, marriage and workplace. It also examined the effects of social contact on attitudes. Using a cross-sectional survey, 202 Ghanaians were purposively sampled to respond to the Disability Social Relations Generalized Disability (DSRGD) scale. Statistical analyses revealed positive attitudes toward persons with physical disabilities among the participants. However, degrees of attitudinal favorability significantly differed in dating, marriage and workplace contexts. Participants' attitudes were more positive in dating context than in marriage context and even more positive in workplace context. In addition, close social contact with persons with disabilities positively influenced participants' attitudes. The findings highlight the need to consider close social contact in specific social contexts in the formulation of policies for promoting favorable attitudes toward persons with physical disabilities.
\end{abstract}

Keywords: Attitudes, Physical Disabilities, Social Context, Social Contact

\section{Introduction}

Persons living with disabilities in developing countries often face a number of structural and socio-cultural barriers that limit their functional ability in society. Among these, unfavorable public attitudes appear key. It is estimated that more than 1 billion people live with various forms of disability worldwide and about $80 \%$ of them are found in developing countries (WHO and WB, 2011). Persons with disabilities in developing countries are often stigmatized, discriminated against, socially excluded from community life and poverty stricken (Maulik and Darmstadt, 2007; WHO and WB, 2011). The hostilities in their environment make them suffer poor mental health outcomes (Hatzenbuehler et al., 2013; Trani et al., 2016).

Public expression of negative attitudes toward persons with physical disabilities hinders their successful integration into community life (Goreczny et al., 2011; Rao, 2004; Zascavage and Keefe, 2004). According to Chubon (1982), negative attitudes toward persons with disabilities can serve as invisible barriers to their pursuit of community involvement and community resources. Stigma associated with disability can prevent persons with disabilities from fully participating in societal life such as seeking employment (Angela, 2015; Boman et al., 2014; 2015), establishing social relationships (Buljevac et al., 2012; Green, 2003; Meininger, 2010) and using health care services (Brodwin and Orange, 2002; Hergenrather et al., 2005; Maulik and Darmstadt, 2007). Negative public attitudes can impact the life of persons with physical disabilities in many harmful ways such as their self-esteem, self-concept and use of vocational and rehabilitation services (Buljevac et al., 2012; Hergenrather and Rhodes, 2007; Kurzban et al., 2010; Trani et al., 2016).

Social distance has been studied in the assessment of attitudes toward individuals with disabilities (Armstrong et al., 2017; Li and Wang, 2013; Link et al., 1999). Social distance refers to the extent to which people are willing to engage in relationships with individuals who are perceived to have socially undesirable traits or characteristics (Link et al., 1999). It is a measure of the degree to which people set boundaries to regulate their social relationships with the stigmatized (Pittam and Gallois, 2000). Stigmatized individuals are often viewed at a social distance from the unstigmatized (Trani et al., 2016).

Research on social distance suggests that individuals' attitudes toward persons with disabilities become more positive as social distance decreases (de Laat et al., 2013; Scior, 2011; Vignes et al., 2009). In general, people who are acquainted with a person with a 
disability tend to express more positive attitudes toward persons with disabilities (Erbaydar et al., 2015; Rosenbaum et al., 1988; Scior, 2011). Erbaydar et al. (2015) observed that close contact and interaction with persons with disabilities were associated with more positive attitudes. Their study revealed more favorable attitudes among employees who had acquaintance with persons with disabilities and employees who were once caretakers of persons with disabilities.

Similarly, Rosenbaum et al. (1988) reported that students who had frequent contacts with a disabled schoolmate or had a disabled friend showed more positive attitudes toward their disabled peers. In a review of 22 studies, Seewooruttun and Scior (2014) found compelling evidence for the positive influence of social contact with persons with disabilities. Despite these findings, some researchers have reported that social contact has no significant effect on attitudes toward persons with physical disabilities (Bossaert et al., 2011; Findler et al., 2007).

Social distance operates within social contexts and plays a significant role in the measurement of attitudes (Ajzen and Fishbein, 1980; Grand et al., 1982). Attitudes are usually expressed toward a specific target, in a given social context and at a given time (Ajzen, 1988; 2001). Given that social distance is a function of social context, it is important to consider social contexts and social relationships in studies that investigate attitudes toward persons with disabilities. Attitudes toward persons with disabilities appear to be less favorable in dating and marriage contexts than in workplace contexts (DeLoach, 1994; Karnilowicz et al., 1994; Grand et al., 1982; Strohmer et al., 1984; Stovall and Sedlacek, 1983).

The theory of social stigma (Goffman, 1963; 1968) helps explain how persons with physical disabilities experience stigma and discrimination. According to this theory, stigma is a construction of deviation from some ideals or expectations, such as the ideal to be free from disfiguring or fatal infectious disease. Whenever this deviation is observed in a person, a powerful discrediting social label is attached to the individual which ultimately changes the way the individual views the self. Individuals who do not meet normative expectations due to undesirable traits become outcasts in the social web of society. Thus, the disconnection between what is desirable and what is actual dents their social identity and isolates them from self and societal acceptance.

Goffman (1968) identified three elements of stigma that characterize disabilities: Blemishes of personal character, stained social identity and physical deformity or defects. In line with Goffman's proposition, Wahl (1999) maintained that persons with physical disabilities are often portrayed as highly dependent, less competent and fundamentally different. Katz (1981), in his interpretation of Goffman's theory, argued that stigma covers a perception of negative characteristics that are directly related to isolation and rejection and result in prejudice and discrimination. Similarly, Parker and Aggleton (2003) indicated that stigma reintroduces inequalities of class, race and gender. The unequal treatment of these categories of people results in unhealthy psychological consequences for disadvantaged groups. According to Goffman (1968), the stigmatized end up internalizing the norms that alienate them from community life. The internalization of these negative labels make persons with physical disabilities experience several forms of psychological problems such as anxiety, low self-esteem, depression and maladaptive adjustment.

Most attitudinal research face the problem of social desirability response bias. Daruwalla (1999) indicated that while the public verbalize positive attitudes toward persons with physical disabilities, they have inward unfriendly feelings. In the light of this, it is necessary to assess attitudes in specific social contexts that elicit truer responses from participants. The rationale for this study therefore is to provide up-to-date information on attitudes toward persons with physical disabilities in specific social contexts in the Ghanaian setting. The current study thus aimed at assessing attitudes in dating, marriage and workplace contexts. These three social contexts are likely situations for the display of actual attitudes toward persons with physical disabilities. In line with the aim, the following hypotheses were tested:

- Ghanaians are likely to have positive attitudes toward persons with physical disabilities

- Attitudes toward persons with physical disabilities will be more positive in the workplace than in dating and marital relationships

- Close social contact with persons with disabilities is likely to produce more positive attitudes toward persons with physical disabilities

\section{Method}

\section{Participants}

Participants were selected from the Greater Accra Region of Ghana. There are 10 geographical regions in Ghana among which is the Greater Accra Region where the capital city of Ghana, Accra, is located. The Greater Accra Region has a diverse and growing population of about 4 million people (GSS, 2012) and serves as the administrative hub for the implementation of welfarerelated issues on disabilities. The diversity of its population made it the best choice for the study. A total of 202 participants were selected through the use of the purposive sampling technique. The participants included individuals in dating relationships, those at the verge of making a decision to enter into marriage and those preparing to enter or already in working professions. Such individuals interact with persons with disabilities in various capacities (e.g., as peer, co-worker, supervisor 
and subordinate). These characteristics were relevant in enhancing contextual analyses of attitudes toward persons with physical disabilities.

In their bid to obtain a representative sample, the researchers used ethnic identity as the main criterion for sample selection, with age, gender, religion, relationship status and educational background as sub-criteria. Four main Ghanaian ethnic groupings were considered in the sample selection namely Akans, Ewes, Northerners and Gas. The Akans, who are the dominant group, were fairly represented by $58.4 \%(n=118)$. Ewes were represented by $18.8 \%(n=38)$, Northerners by $16.8 \%(n=34)$ and Gas by $6.0 \%(n=12)$. The ages of the participants ranged from 18 to 67 years $(M=31.22, S D=9.54)$. There were $45.5 \%$ males $(n=92)$ and $54.5 \%$ females $(n=110)$, reflective of the female dominance in the population. In terms of religious affiliation, $86.6 \%$ of the participants $(n$ $=175$ ) were Christians, reflective of the Christian dominance of the Ghanaian population. Muslims constituted $12.4 \%(n=25)$ and Traditionalists constituted only $1.0 \%(n=2)$ of the sample. It must be noted that whilst many Ghanaians cling to their traditional beliefs and practices, only a few identify with the Traditional African Religion (Abotchie, 2008). Regarding relationship status, $24.8 \%$ of the participants were single $(n=50)$, $58.9 \%$ were dating $(n=119), 14.9 \%$ were married $(n=$ $30)$ and $1.5 \%$ were divorced $(n=3)$. Finally, educational background analyses revealed that participants with basic education were $10.4 \%(n=21)$, those with secondary education were $42.6 \%(n=86)$ and those with tertiary education were $47.0 \%(n=95)$. These characteristics indicate that the study sample was all inclusive and fairly representative of the Ghanaian population.

\section{Design}

Quantitative cross-sectional survey was employed. The design involved the accumulation of data through the use of carefully and systematically framed questions. This design allowed the researchers to obtain self-report information of participants regarding their attitudes toward persons with physical disabilities.

\section{Measures}

Attitudes toward persons with physical disabilities were assessed using the Disability Social Relations Generalized Disability (DSRGD) Scale created by Hergenrather and Rhodes (2007). The DSRGD is an 18item scale that considers the multidimensionality of attitudes toward persons with disabilities in specific social contexts. Each item is evaluated using a 5-point Likert response scale ( $5=$ strongly agree; $4=$ agree, $3=$ Neutral; 2 = disagree, 1 = strongly disagree). DSRGD has three subscales that reflect three specific social contexts: Dating, marriage and work. The dating subscale is a 6-item measure of attitudes toward persons with disabilities in the social context of dating. It assesses friendship, level of comfort in dating, worries about what others think, embarrassment regarding helping one's date in public, willingness to have a sexual relationship and comfort having sexual intercourse. A sample item of the dating subscale is "When dating a person with a disability, I would not feel uncomfortable if people would stare." The marriage subscale is a 6-item measure of attitudes toward persons with disabilities within the social context of marriage. It assesses marital consideration, marital intent, partner dependence, comfort making love, partner's ability to earn income and partner responsibility as a parent. An item of this subscale is "A spouse with a disability would not be too dependent on me." Finally, the work subscale is a 6-item measure of attitudes toward persons with disabilities within the social context of work. It assesses co-worker relationships, requirement of accommodation assistance, considerations of words during conversation, co-worker interaction, co-worker socialization and ability to execute job duties. A sampled item of this subscale is "In the workplace, I would have a close relationship with a co-worker who has a disability."

Empirical studies have confirmed the psychometric value of the DSRGD. Among a college sample, Gordon et al. (1990) found significant differences in attitudes toward the disabled within the social contexts of dating, marriage and work. It is on this basis that the DSRGD was found useful for the current study. Appreciable values of internal consistency reliability coefficients have been reported for the DSRGD scale and its subscales. Based on Loevinger's (1954) criteria, excellent Cronbach's alpha coefficients were reported for the DSRGD (0.89) and the dating subscale (0.92); and good Cronbach's alpha coefficients for the marriage $(0.83)$ and the work (0.81) subscales (Hergenrather and Rhodes, 2007). In the present study, DSRGD recorded 0.86 Cronbach's alpha coefficient; 0.87 for the dating subscale; 0.81 for the marriage subscale; and 0.79 for the workplace subscale. These coefficients suggest that the DSRGD is a reliable instrument even in the Ghanaian cultural context. According to De Vaus (2002), a scale with Cronbach's alpha coefficient of 0.70 or more should be considered reliable.

\section{Procedure}

The researchers and 14 research assistants who were mainly students of the University of Ghana constituted a research team for data collection. A letter of introduction was obtained from the Department of Psychology of the University of Ghana. The letter introduced the researchers and their assistants as faculty members and students of the department respectively. The research assistants were chosen based on their affiliation to and familiarity with, communities in the region where the study was to be conducted. They were graduate students pursuing their MPhil studies at the Department of Psychology of the University of Ghana. They had each 
completed courses in experimental psychology, research methodology and statistics for psychologists. In addition, they had exposure to children living with disabilities. Their fundamental knowledge in research and good understanding of issues relating to disabilities made them a good choice as research assistants for the study. After declaring their voluntary commitment to the research project, the research assistants underwent a dayorientation program during which they received detailed information about the nature and purpose of the study, skills and ethics regarding data collection and protocols to be observed while collecting data.

After the training, the research team administered the research questionnaires in their respective communities during their long vacation. In order to obtain informed consent of participants, team members first explained the purpose and significance of the study to prospective research participants. Team members also assured prospective participants of utmost confidentiality in their participation and responses. After obtaining informed consent from a participant, he or she was given the questionnaire and allowed ample time to provide appropriate responses. Participation was voluntary and participants reserved the right to withdraw from the study at all times. No financial or material inducement was offered to participants. Participants were reminded to read instructions before responding to questions in the various sections of the questionnaire. Team members received questionnaires upon completion and expressed gratitude to respondents for their participation. Upon resumption of the semester, the research team met and collated the questionnaires for analysis. The researchers coded and analyzed the questionnaires using the Statistical Package for Social Sciences (SPSS) program. The analysis was conducted in line with the research hypotheses.

\section{Data Analyses}

The one-sample $t$ test, the independent-samples $t$ test, the Pearson product-moment correlation coefficient (Pearson $r$ ) test, the repeated measures test and the Least Significant Difference $(L S D)$ post hoc test were employed in the data analyses. The use of these tests was appropriate because the dependent variable (i.e., attitudes) was measured on the interval scale and the distribution of data was normal in form. The one-sample $t$ test was used to analyze the first research hypothesis which assessed attitudes of the sample against the expected attitudes of the general population (denoted with the average score on the scale). The repeated measures test was used to analyze the second research hypothesis which compared attitudes of the respondents in three different contexts (dating, marriage and workplace). A significant $F$-ratio led to the use of the $L S D$ post hoc test. The independent-samples $t$ test was used to analyze the third research hypothesis which compared attitudes of two mutually-exclusive groups (i.e., respondents with close social contact and respondents with distant contact). It was also used to assess the impact of certain demographic variables (i.e., gender and educational background) on respondents' attitudes toward persons with physical disabilities. Finally, the Pearson $r$ test was used to determine the strength and direction of relationship existing between respondents' age (measured on the interval scale) and their attitudes toward persons with physical disabilities.

\section{Results}

Table 1 shows significant positive attitudes toward persons with physical disabilities among the study sample $\left(t_{(201)}=9.99, p=0.000\right)$. The mean score reveals that respondents' attitudes $(M=60.41, S D=9.11)$ were significantly higher than average (Average $=54.00$ ). Although age had a significant positive correlation with attitudes $(r=0.15, p<0.05)$ (Table 2$)$, there was no significant impact of gender $\left(t_{(200)}=1.11, p>0.05\right)$ and education $\left(t_{(200)}=-0.07, p>0.05\right)$ on respondents' attitudes toward persons with physical disability (Table $3)$. The data thus confirm the prediction that "Ghanaians are likely to have positive attitudes toward persons with physical disabilities."

Table 4 shows that attitudes toward persons with physical disabilities significantly differed depending on context $\left(F_{(1,2)}=16.84, p=0.000\right)$. Attitudes toward persons with physical disabilities were most positive in workplace context $(M=20.96, S D=3.02)$, more positive in dating context $(M=20.15, S D=4.49)$ and positive in marriage context $(M=19.30, S D=4.12)$. The data support the second hypothesis that "Attitudes toward persons with physical disabilities will be more positive in workplace context than in dating and marital relationships."

Table 5 displays the independent-samples $t$ test results on the effect of close social contact on attitudes toward persons with physical disabilities. It reveals a significant effect of close social contact on attitudes toward persons with physical disabilities among the study sample $\left(t_{(200)}=3.12, p<0.01\right)$ and in the contexts of dating $\left(t_{(200)}=2.45, p<0.05\right)$, marriage $\left(t_{(200)}=2.52, p\right.$ $<0.05)$ and workplace $\left(t_{(200)}=2.25, p<0.05\right)$. Respondents with close social contact with persons with disabilities were more positive in their attitudes toward persons with physical disabilities $(M=62.85, S D=8.27)$ than those without close social contact $(M=58.84, S D=$ 9.31). This observation was consistent across dating, marriage and workplace contexts (Table 5). These results provide evidence in support of the third research hypothesis that "Close social contact with persons with physical disabilities is likely to produce more positive attitudes toward persons with physical disabilities." 
Table 1: Attitudes toward persons with physical disabilities

\begin{tabular}{lllllll}
\hline & $N$ & Mean $(S D)$ & Average & $t$ & $d f$ & $p$ \\
\hline Attitudes & 202 & $60.41(9.11)$ & 54.00 & 9.99 & 201 & 0.000 \\
\hline
\end{tabular}

Table 2: Correlations between age and attitudes toward persons with physical disabilities

\begin{tabular}{lllll}
\hline & 1 & 2 & 3 & 4 \\
\hline 1. Age & - & & & 5 \\
2. General attitude & $0.15^{*}$ & - & & \\
3. Dating attitude & 0.08 & $0.84^{* *}$ & - & $-59^{* *}$ \\
4. Marriage attitude & $0.12^{* *}$ & $0.86^{* *}$ & $0.23^{* *}$ & $0.35^{* *}$ \\
5. Workplace attitude & $0.17^{* *}$ & $0.23^{* *}$ & - \\
\hline
\end{tabular}

$* \mathrm{p}<0.05 ; * * \mathrm{p}<0.01$

Table 3: Impact of gender and educational background on attitudes toward persons with physical disabilities

\begin{tabular}{|c|c|c|c|c|c|}
\hline Variables & $n$ & Mean & $d f$ & $t$ & $p$ \\
\hline \multicolumn{6}{|l|}{ Gender } \\
\hline Males & 92 & $61.19(9.69)$ & 200 & 1.11 & 0.268 \\
\hline Females & 110 & $59.76(8.59)$ & & & \\
\hline \multicolumn{6}{|c|}{ Educational background } \\
\hline Low education ${ }^{a}$ & 44 & $60.27(9.46)$ & 200 & -0.07 & 0.942 \\
\hline High education $^{b}$ & 158 & $60.42(9.10)$ & & & \\
\hline
\end{tabular}

${ }^{a}$ Low education denotes educational levels up to second cycle of the Ghanaian educational system.

${ }^{b}$ High education denotes educational levels beyond second cycle of the Ghanaian educational system

Table 4: Attitudes toward persons with physical disabilities in dating, marriage and workplace contexts

\begin{tabular}{llllll}
\hline Contexts & $N$ & Mean $(S D)$ & $d f$ & $F$ & 16.84 \\
\hline Dating & 202 & $20.15^{*}(4.49)$ & 2 & \\
Marriage & 202 & $19.30^{*}(4.12)$ & & \\
Workplace & 202 & $20.96^{*}(3.02)$ & & \\
\hline
\end{tabular}

*Least Significant Difference (LSD): $\mathrm{p}<0.05$

Table 5: Effect of social contact on attitudes toward persons with physical disabilities

\begin{tabular}{|c|c|c|c|c|c|}
\hline Social contact & $n$ & Mean $(S D)$ & $d f$ & $t$ & $p$ \\
\hline \multicolumn{6}{|l|}{ General attitudes } \\
\hline Close contact & 79 & $62.85(8.27)$ & 200 & 3.12 & 0.002 \\
\hline Distant contact & 123 & $58.84(9.31)$ & & & \\
\hline \multicolumn{6}{|l|}{ Dating attitude } \\
\hline Close contact & 79 & $21.10(4.16)$ & 200 & 2.45 & 0.015 \\
\hline Distant contact & 123 & $19.54(4.60)$ & & & \\
\hline \multicolumn{6}{|l|}{ Marriage attitude } \\
\hline Close contact & 79 & $20.20(4.01)$ & 200 & 2.52 & 0.012 \\
\hline Distant contact & 123 & $18.72(4.10)$ & & & \\
\hline \multicolumn{6}{|l|}{ Workplace attitude } \\
\hline Close contact & 79 & $21.54(2.84)$ & 200 & 2.25 & 0.026 \\
\hline Distant contact & 123 & $20.58(3.08)$ & & & \\
\hline
\end{tabular}

\section{Discussion}

The purpose of the research was to provide contextual analyses on attitudes toward persons with physical disabilities. Based on the premise that measurements of public attitudes toward persons with disabilities ought to be situated in social contexts, the researchers examined attitudes of Ghanaians toward persons with physical disabilities within the social contexts of dating, marriage and workplace. They also assessed the impact of social contact on attitudes towards persons with physical disabilities. Findings of the study revealed that Ghanaians generally have positive attitudes toward persons with physical disabilities. However, attitudes toward persons with physical disabilities were less positive in marriage context than in dating context but more positive in workplace context. Close social contact with persons with disabilities had a positive influence on attitudes toward persons with physical disabilities.

Consistent with prediction, it was observed that Ghanaians have positive attitudes toward persons with physical disabilities. This points out a changing trend in Ghanaians' attitudes towards persons with physical disabilities. It suggests that the traditional beliefs about 
disabled individuals are consistently paving way for modern conceptions of disability within the Ghanaian society. Thus, the current finding has a good fit with the transitional socio cultural milieu of Ghana. The finding also reinforces that of Walker (1982) which showed above-average favorability ratings of Ghanaians' attitudes toward the mentally retarded.

Though the attitudes of Ghanaians toward persons with physical disabilities were generally positive, significant differences were observed in specific social contexts. Whenever social contexts required greater intimacy and bond, attitudes toward persons with physical disabilities became less positive. Attitudes toward persons with physical disabilities were less positive in marital relationship compared to dating and workplace contexts. This may be due to the fact that marriage brings individuals closer together and imposes the responsibility of complete acceptance and support for each other. It is in such context of greater intimacy that individuals make less favorable evaluation of persons with physical disabilities, particularly as a potential marriage partner. Thus, people would likely date persons with physical disabilities or, even more likely, work with them, than to have a marital relationship with them. Likewise, attitudes toward persons with physical disabilities were less positive in dating relationship than in the workplace context. Just like marriage, dating imposes certain responsibilities on partners. However, unlike marriage, one can easily opt out of dating relationship. Compared with dating relationship, individuals may prefer to interact with persons with physical disabilities in the workplace context. These findings clearly show that the degree of intimacy in social contexts defines the nature of individuals' attitudes toward persons with physical disabilities.

In line with expectation, it was observed that respondents with close social affiliation with persons with disabilities showed more positive attitudes toward persons with physical disabilities than those without such affiliation. This observation sustains earlier research findings that prior or current social contact with a disabled person exerts a positive influence on attitudes toward persons with disabilities (Erbaydar et al., 2015; Rosenbaum et al., 1988; Scior, 2011). Individuals' attitudes toward persons with disabilities become more favorable as social distance decreases (de Laat et al., 2013; Vignes et al., 2009). In the present study, individuals who reported some form of affiliation or continuous social contact with a person with physical disabilities were more positive in their attitudes than those without such contact or affiliation. This suggests that social contact is vital in promoting positive attitudes toward persons with physical disabilities.

Not all studies have found positive influence of social contact on attitudes toward persons with disabilities. Evidence presented by Bossaert et al. (2011) and
Findler et al. (2007) showed no effect of acquaintance or social contact on attitudes toward persons with disabilities. In the case of Bossaert et al. (2011), social contact nearly predicted attitudes. Perhaps, the method of investigation may account for these null findings. Having distinguished between knowing someone with a disability and having a disabled friend, Vignes et al. (2009) found positive attitudes among individuals with a disabled friend but not among those with mere contact with disabled persons. For social contact to predict attitudes, it is necessary to consider the degree of intimacy within social relationships. Close social contact like friendship is more likely to predict favorable attitudes than distant or less-intimate social contact.

Despite the remarkable findings, the study is limited in scope. Although human disabilities are expressed in various forms such as intellectual disability, mental disability and physical disability, the present study focused solely on physical disabilities. This means that the findings and conclusions drawn in this study should best be understood and interpreted within the context of physical disabilities.

\section{Recommendations}

As revealed in the study, attitudes of Ghanaians toward persons with physical disabilities were less positive in dating and marriage contexts than in workplace context. Consequently, there is a need for interventional measures that will make persons with physical disabilities become more attractive in dating and marital relationships. Such measures should aim at improving the living standards and the general wellbeing of persons with physical disabilities. In this regard, the government should ensure that the needs and aspirations of persons with disabilities are catered for and their rights protected in order for them to realize their utmost potential. In addition, the government should make available and accessible some material and/or financial benefits for the improvement of the living standard of persons with disabilities, especially those living below the poverty threshold. Such benefits may be in the form of affordable housing, unemployment allowances, healthcare coverage and accessible recreational facilities. At the moment, persons with disabilities in most developing countries including Ghana lack these benefits. Improving the living conditions of persons with disabilities will elicit feelings of self-worth and self-respect among persons with disabilities and also create a more positive perception among the public. This ultimately will make persons with physical disabilities become more attractive for dating and marital relationships.

Based on the finding that close social contact with persons with disabilities leads to more positive attitudes toward persons with physical disabilities, it is recommended that greater social contact with disabled persons be promoted in schools, workplaces and the community at large. In the view of Erbaydar et al. 
(2015), interventions aimed at increasing awareness of and interaction with, persons with disabilities may be useful in efforts to improve attitudes toward persons with disabilities. Close social contact and interaction with persons with physical disabilities can be promoted through the following ways.

First, educational authorities and teachers should create environments that encourage interaction between the physically-disabled and their physically-abled counterparts. Government should institute policies that will ensure that students with disabilities and those without disabilities are assigned to same dormitories in schools. Such early contact and interaction will enhance greater understanding and positive feelings toward persons with disabilities.

At the workplace, employers should put in place interventions that promote co-worker interaction and appreciation of diversity to make employees learn to understand and appreciate disabled employees and truly accept them. At the same time, employers especially those in private businesses should provide a conducive environment for persons with disabilities to be involved in productive activities in order to foster their development and the utilization of available resources to enhance their effectiveness. Their effectiveness at work will enable them to win the respect of their abled counterparts and create positive public perception on disability in general. Government should institute policies that will make employees with disabilities and those without disabilities share offices and other occupational facilities in order to create opportunities for close social contact. This will be useful in promoting more positive attitudes toward persons with disabilities.

Finally, systematic interventional measures should be instituted at the macrostructural level to address sociocultural beliefs and practices that limit social contact with persons with disabilities. An effective way to change traditional negative beliefs and practices against persons with disabilities is through public education. After a critical review of 22 studies, Seewooruttun and Scior (2014) concluded that the most promising interventional measures are those aimed at increasing public knowledge of disability through education. Ghanaians should be well educated about the scientific causes of physical disabilities and the significant contributions that persons with physical disabilities could make, if allowed, to national development. They must be educated to dispel prejudices and stereotypes assigned to physical disabilities and accompanying discriminatory behaviors. For instance, the idea that persons with disabilities cannot serve as 'chiefs' in the Ghanaian chieftaincy institution should be vehemently confronted and condemned. Conscious and concerted efforts should be made to highlight and bring to the fore the competence and capabilities of persons with disabilities. Particularly, promoting competent individuals with disabilities into positions of power will serve as empowerment to persons with disabilities and, at the same time, help dispel public prejudices against them.

\section{Conclusion}

The study has provided contextual knowledge on attitudes toward persons with physical disabilities. It is confirmed in the study that attitudes toward persons with physical disabilities are functions of social context. While Ghanaians generally portrayed positive attitudes toward persons with physical disabilities, their attitudes appeared less positive in marriage context than in dating and workplace contexts and less positive in dating context than in workplace context, suggesting that attitudes toward persons with physical disabilities become less positive in situations where greater intimacy is required. As DeLoach (1994) noted, people are more willing to interact with persons with disabilities as co-workers than as potential dating or marriage partners. Consistent with literature, close social contact led to more positive attitudes among respondents. This suggests that the degree of intimacy in a social context largely defines the nature of attitudes toward persons with physical disabilities. The findings thus highlight the need for policy makers and advocacy groups to consider the creation of close social contacts between the general public and persons with physical disabilities. It is hoped that should government and other relevant stakeholders pay heed to the actiondriven recommendations suggested in this research, public perception and attitudes toward persons with physical disabilities will improve.

\section{Acknowledgement}

The authors acknowledge the significant role played by their research assistants in data collection.

\section{Funding Information}

The authors received no financial support for this research.

\section{Author's Contributions}

Christopher M. Amissah: Conceived the study; planned, designed and conducted the study; developed the manuscript.

Christopher K. Gadosey: Supervised data collection; planned, designed and conducted the study; developed the manuscript.

Kingsley Nyarko and Collins B. Agyemang: Planned, designed and conducted the study; developed the manuscript.

\section{Ethics}

Authors have no conflict of interest. All ethical requirements on research with human participants were fully upheld. 


\section{References}

Abotchie, C., 2008. Social Change in Ghana. 1st Edn., Ghana Universities Press, Accra.

Ajzen, I., 1988. Attitudes, Personality and Behavior. 1st Edn., Dorsey, Chicago.

Ajzen, I., 2001. Nature and operations of attitudes. Ann. Rev. Psychol., 52: 27-58.

Ajzen, I. and M. Fishbein, 1980. Understanding Attitudes and Predicting Social Behavior. 1st Edn., PrenticeHall, Englewood Cliffs, ISBN-10: 0139364439, pp: 278.

Angela, B.M., 2015. Employment of persons with disabilities. Proc. Soc. Behav. Sci., 191: 979-983.

Armstrong, M., C. Morris, C. Abraham and M. Tarrant, 2017. Interventions utilizing contact with people with disabilities to improve children's attitudes towards disability: A systematic review and metaanalysis. Disability Health J., 10: 11-22.

Boman, T., A. Kjellberg, B. Danermark and E. Boman, 2014. Can people with disabilities gain from education? Similarities and differences between occupational attainment among persons with and without disabilities. Work, 49: 193-204.

Boman, T., A. Kjellberg, B. Danermark and E. Boman, 2015. Employment opportunities for persons with different types of disability. Eur. J. Disability Res., 9: 116-129.

Bossaert, G., H. Colpin, S.J. Pijl and K. Petry, 2011. The attitudes of Belgian adolescents towards peers with disabilities. Res. Dev. Disabilities, 32: 504-509.

Brodwin, M.G. and L.M. Orange, 2002. Attitudes Toward Disability. In Rehabilitation Services: An Introduction for the Human Services Professional Andrew, J.D. and C.W. Faubion (Eds.), Osage Beach, MO: Aspen Professional Services, pp: 174-197.

Buljevac, M., M. Majdak and Z. Leutar, 2012. The stigma of disability: Croatian experiences. Disability Rehabilitat., 34: 725-732.

Chubon, R., 1982. An analysis of research dealing with the attitudes of professionals toward disability. J. Rehabilitat., 48: 25-30.

Daruwalla, P., 1999. Attitudes, disability and the hospitality and tourism industry. $\mathrm{PhD}$ Thesis, University of Newcastle, Australia.

de Laat, S., E. Freriksen and M.P.J. Vervloed, 2013. Attitudes of children and adolescents toward persons who are deaf, blind, paralyzed or intellectually disabled. Res. Dev. Disabilities, 34: 855-863.

De Vaus, D., 2002. Surveys in Social Research. 1st Edn., Taylor and Francis, London, ISBN-10: 0415268575, pp: 379.

DeLoach, C., 1994. Attitudes toward disability: Impact on sexual development and forging of intimate relationships. J. Applied Rehabilitat. Counsel., 25: 18-25.
Erbaydar, N.P., O.K. Caman and N. Cilingiroglu, 2015. How do municipality employees in Ankara approach persons with disabilities? Disability Health J., 6: 391-398.

Findler, L., N. Vilchinsky and S. Werner, 2007. The Multidimensional Attitudes Scale toward persons with disabilities (MAS). Rehabilitat. Counsel. Bull., 50: 166-176.

GSS, 2012. Population and Housing Census: Summary Report of Final Results. 1st Edn., Ghana Statistical Service, Accra.

Goffman, E., 1963. Stigma. 1st Edn., Prentice Hall, Englewood Cliffs.

Goffman, E., 1968. Theory of Social Stigma. 1st Edn., Prentice Hall, Englewood Cliffs, NJ.

Gordon, E.D., P.M. Minnes and R.R. Holden, 1990. The structure of attitudes toward persons with a disability, when specific disability and context are considered. Rehabilitat. Psychol., 35: 79-90.

Goreczny, A.J., E. Bender, G. Caruso and C.S. Feinstein, 2011. Attitudes toward individuals with disabilities: Results of a recent survey and implications of those results. Res. Dev. Disabilities, 32: 1596-1609.

Grand, S.A., J.E. Bernier and D.C. Strohmer, 1982. Attitudes toward disabled persons as functions of social context and specific disability. Rehabilitat. Psychol., 27: 165-174.

Green, S.E., 2003. "What do you mean 'what's wrong with her?": Stigma and the lives of families of children with disabilities. Soc. Sci. Med., 57: 1361-1374.

Hatzenbuehler, M.L., J.C. Phelan and B.G. Link, 2013. Stigma as a fundamental cause of population health inequalities. Am. J. Public Health, 103: 813-821.

Hergenrather, K. and S. Rhodes, 2007. Exploring undergraduate student attitudes toward persons with disabilities: Application of the disability social relationship scale. Rehabilitat. Counsel. Bull., 50: 66-77.

Hergenrather, K.C., S.D. Rhodes and R.S. McDaniel, 2005. Correlates of job placement: Public rehabilitation counselors and consumers living with AIDS. Rehabilitat. Counsel. Bull., 48: 157-167.

Karnilowicz, W., W. Sparrow and A. Shinkfield, 1994. High school students' attitudes toward performing social behaviors with mentally retarded and physically disabled peers. J. Soc. Behav. Personality, 9: 65-80.

Katz, I., 1981. Stigma: A Social Psychological Analysis. 1st Edn., Lawrence Erlbaum Associates, Inc., Hillsdale.

Kurzban, S., L. Davis and J.S. Brekke, 2010. Vocational, social and cognitive rehabilitation for individuals diagnosed with schizophrenia: A review of recent research and trends. Curr. Psychiatry Rep., 12: 345-355. 
Li, C. and C.K.J. Wang, 2013. Effect of exposure to special Olympic Games on attitudes of volunteers towards inclusion of people with intellectual disabilities. J. Applied Res. Intellectual Disabilities, 26: 515-521.

Link, B.G., J.C. Phelan, M. Bresnahan, A. Stueve and B.A. Pescolido, 1999. Public conceptions of mental illness: Labels, causes, dangerousness and social distance. Am. J. Public Health, 89: 1328-1333.

Loevinger, J., 1954. The attenuation paradox in test theory. Psychol. Bull., 51: 493-504.

Maulik, P.K. and G.L. Darmstadt, 2007. Childhood disability in low- and middle-income countries: Overview of screening, prevention, services, legislation and epidemiology. Pediatrics, 120: S1-S55.

Meininger, H.P., 2010. Connecting stories: A narrative approach of social inclusion of persons with intellectual disability. Alter, 4: 190-202.

Parker, R. and P. Aggleton, 2003. HIV and AIDS-related stigma and discrimination: A conceptual framework and implications for action. Soc. Sci. Med., 57: 13-24.

Pittam, J. and C. Gallois, 2000. Malevolence, stigma and social distance: Maximizing intergroup differences in HIV/AIDS discourse. J. Applied Commun. Res., 28: 24-43.

Rao, S., 2004. Faculty attitudes and students with disabilities in higher education: A literature review. College Student J., 38: 191-199.

Rosenbaum, P.L., R.W. Armstrong and S.M. King, 1988. Determinants of children's attitudes toward disability: A review of evidence. Children's Health Care, 17: 32-39.

Scior, K., 2011. Public awareness, attitudes and beliefs regarding intellectual disability: A systematic review. Res. Dev. Disabilities, 32: 2164-2182.
Seewooruttun, L. and K. Scior, 2014. Interventions aimed at increasing knowledge and improving attitudes towards people with intellectual disabilities among lay people. Res. Dev. Disabilities, 35: 3482-3495.

Stovall, C. and W. Sedlacek, 1983. Attitudes of male and female university students toward students with different physical disabilities. College Student Personnel, 26: 325-330.

Strohmer, D.C., S.A. Grand and M.J. Purcell, 1984. Attitudes toward persons with a disability: An examination of demographic factors, social context and specific disability. Rehabilitat. Psychol., 29: 131-145.

Trani, J.F., E. Ballard and J.B. Pena, 2016. Stigma of persons with disabilities in Afghanistan: Examining the pathways from stereotyping to mental distress. Soc. Sci. Med., 153: 258-265.

Vignes, C., E. Godeau, M. Sentenac, N. Coley and F.H. Navarro et al., 2009. Determinants of students' attitudes toward peers with disabilities. Dev. Med. Child Neurol., 51: 473-479.

Wahl, O.F., 1999. Mental health consumers' experience of stigma. Schizophrenia Bull., 25: 467-478.

Walker, S., 1982. A comparison of attitudes and knowledge of Ghanaian college students relative to the mentally retarded. Applied Res. Mental Retardat., 3: 163-174.

WHO and WB, 2011. World Report on Disability. 1st Edn., World Health Organization, Geneva ISBN-10: 9241564180, pp: 325.

Zascavage, V.T. and C.H. Keefe, 2004. Students with severe speech and physical impairments: Opportunity barriers to literacy. Focus Autism Other Dev. Disorders, 19: 223-234. 